Revista Destaques Acadêmicos, Lajeado, v. 12, n. 3, 2020. ISSN 2176-3070

DOI: http://dx.doi.org/10.22410/issn.2176-3070.v12i3a2020.2516

http://www.univates.br/revistas

\title{
O USO DE METODOLOGIAS ATIVAS EM AULAS DE ENFERMAGEM
}

\author{
Lucimara Fiorese ${ }^{1}$, Michele Ravel Simões ${ }^{2}$, Cristiana Lenhardt ${ }^{3}$, \\ Rosemeri Camargo ${ }^{4}$, Alana Mors ${ }^{5}$, Bibiana de Andrade ${ }^{6}$
}

\begin{abstract}
Resumo: Este artigo objetivou descrever o processo de ensino, baseado em metodologias ativas de aprendizagem na disciplina de Saúde do Idoso do curso Técnico em Enfermagem, mediante aprendizagem baseada em problemas, na qual, os estudantes deveriam, ao final do processo, desenvolver um projeto inovador, voltado para atender idosos, bem como, identificar os resultados alcançados com a metodologia proposta. Sendo pesquisa aplicada, estudo de caso, pesquisa-ação e metodologia qualitativa, realizada na disciplina de Saúde do Idoso, ministrada no curso Técnico de Enfermagem. Os resultados demonstram que soluções simples podem surgir do uso de metodologias ativas e aprendizagens baseadas em problemas, destes métodos nasceram dois projetos que visam melhorar a locomoção de pessoas idosas: andador que vira assento e bengala sustentável com compartimento para medicamentos.
\end{abstract}

Palavras-chave: Aprendizagem Baseada em Problemas. Idoso. Metodologias Ativas. Técnico em Enfermagem.

1 Secretária Executiva. Especialista em Gestão de Pessoas e MBA em Finanças. Docente de Metodologia e Técnicas de Pesquisa e orientadora de trabalhos de conclusão.

2 Enfermeira. Especialista em Saúde pública com ênfase em saúde da família e Docência na educação profissional. Docente do curso técnico em Enfermagem.

3 Cursando Técnico em Enfermagem.

4 Cursando Técnico em Enfermagem.

5 Cursando Técnico em Enfermagem.

6 Cursando Técnico em Enfermagem. 


\section{INTRODUÇÃO}

Atuar como profissional na área de enfermagem é um desafio que exige tomada de decisão, trabalho em equipe e conhecimento prévio sobre processos e procedimentos do cuidado com os pacientes, ao mesmo tempo, que é preciso entender que ali estão seres humanos que precisam de atenção, cuidado e estão, normalmente, debilitados. Por isso, este profissional precisa ter capacidade inerente e habilidade para ajudar as pessoas.

Oliveira e Pontes (2011) enfatizam que o cuidado é um fenômeno primordial para a existência humana, por isso, o homem que não recebe cuidado desestrutura-se, definha; a vida dele perde sentido, levando-o à morte. Neste contexto, o cuidado é o maior instrumento de trabalho da enfermagem, permitindo que pacientes e profissionais de enfermagem interajam. Muito mais que trabalhar os aspectos técnicos, há elementos essenciais no cuidado em enfermagem como ouvir, apoiar, respeitar o indivíduo, tocar e oferecer segurança, alinhando este preceito ao que conhecemos como humanização, que Ferreira, Condori e Souza (2019) explicam ser o resgate do respeito à vida humana.

Assim sendo, a formação deste profissional exige a construção dinâmica do conhecimento, um processo que permita ao estudante maior interação com a realidade, como o uso de metodologias ativas ou aprendizagem baseada em problemas. Para Bordenave e Pereira (2004), as metodologias ativas significam viabilizar o envolvimento do estudante no processo de ensino e de aprendizagem, tornando o estudante participante ativo no desenvolvimento do saber por meio de estímulos e desafios, abrangendo o conhecimento e análise de problemas. Já Araújo e Sastre (2016, p. 17) declaram que:

[...] 'aprendizagem baseada em problemas' é uma expressão que abrange diferentes enfoques do ensino e da aprendizagem. Ela pode se referir a conceitos didáticos baseados somente na resolução de problemas ou a conceitos que combinem cursos tradicionais com resolução de problemas por meio do trabalho com projetos. Ambos têm em comum o foco no processo de aprendizagem do estudante.

Partindo da necessidade do profissional de enfermagem com o cuidado ao outro e dos anseios de tornar o processo de ensino e de aprendizagem dinâmico, este estudo tem como objetivo, descrever o processo de ensino, baseado em metodologias ativas de aprendizagem na disciplina de Saúde do Idoso do curso Técnico em Enfermagem, mediante aprendizagem baseada em problemas, na qual, os estudantes deveriam, ao final do processo, desenvolver um projeto inovador, voltado para atender idosos, bem como, identificar os resultados alcançados com a metodologia proposta. 


\section{REFERENCIAL TEÓRICO}

De forma explicativa, o processo de aprendizagem humana é embasado nos princípios organizacionais da cognição, em que conhecimento e entendimento de informações se valorizam, não sendo apenas uma técnica de memorização mecânica. Assim, sugere-se que há uma relação de forma que os conteúdos se agregam de forma hierarquizada e complexa, ligando conhecimentos e proporcionando aprendizagem e crescimento cognitivo aos discentes (OLIVEIRA; PONTES, 2011).

A partir deste contraponto, aborda-se que a metodologia da Aprendizagem Baseada em Problemas (ABP) busca a resolução de um problema usado para iniciar, motivar e focar o estudante na construção do próprio conhecimento, utilizando diferentes metodologias e espaços além do convencional de sala de aula. Ribeiro (2010, p. 13, grifo do autor) enfatiza que:

A aprendizagem baseada em problemas (ABP) - Problem-Based Learning (PBL), como é conhecida mundialmente - é essencialmente uma metodologia de ensino-aprendizagem caracterizada pelo uso de problemas da vida real para estimular o desenvolvimento do pensamento crítico e das habilidades de solução de problemas e a aquisição de conceitos fundamentais da área de conhecimento em questão. De forma geral, a PBL, busca, junto com outras metodologias educacionais com base construtivista, responder a alguns dilemas colocados à educação profissional contemporânea [...]. O PBL também parece satisfazer [...] uma formação que integre a teoria à prática e o mundo acadêmico ao do trabalho, promovendo - além do domínio do conhecimento específico - o desenvolvimento de habilidades e atitudes profissionais e cidadãs.

Os problemas são aplicados para que o discente construa a solução, aprenda, informe-se sobre a teoria e busque o resultado. Neste caso,

[...] um problema é colocado antes de a teoria ser apresentada aos alunos, em grupos pequenos, que passam a explorá-lo e a levantar hipóteses, facilitados eficazmente por um tutor que ativa seu conhecimento prévio - que pode ser tanto útil como equivocado - e os ajuda a rememorar conceitos e mecanismos (RIBEIRO, 2010, p. 21).

Assim sendo, pode-se inferir que na $A B P$ o estudante torna-se protagonista do processo de desenvolvimento do conhecimento, já que ele se encarregará da responsabilidade para alcançar seus objetivos educacionais. Neste contexto, o discente necessita se autogerir e buscar no professor um apoio para o seu desenvolvimento (BERBEL, 2011). Para Araújo e Sastre (2016, p. 26, grifo dos autores), a aprendizagem baseada em problemas: 
[...] significa que conhecimentos de livros didáticos tradicionais são substituídos por conhecimentos necessários à resolução de problemas teóricos. O conceito educativo de aprendizagem baseada em problemas afasta a perspectiva da compreensão de conceitos comuns e a situa na capacidade de desenvolver novos conhecimentos. O objetivo do trabalho com projetos é 'aprender a fazer' ou 'aprender na ação'. O projeto pode ser organizado com a perspectiva do saber como para alcançar a formação nas habilidades profissionais, ou mesmo com a perspectiva de saber por que para a aquisição de habilidades metodológicas de análise e aplicação de problemas.

Os objetivos da ABP propendem, em última análise, aplicar técnicas na busca da solução de determinado problema; no entanto, não é somente esse o desafio no âmbito da educação, visto que os objetivos educacionais da $A B P$ abrangem:

(a) aprendizagem ativa, por meio da colocação de perguntas e busca de respostas; (b) aprendizagem integrada, por intermédio da colocação de problemas para cuja solução é necessário o conhecimento de várias subáreas; (c) aprendizagem cumulativa, mediante a colocação de problemas gradualmente mais complexos até atingir aqueles geralmente enfrentados por profissionais iniciantes; e (d) aprendizagem para compreensão, em vez de para a retenção de informações, mediante a alocação de tempo para a reflexão, feedback frequente e oportunidades para praticar o que foi aprendido (RIBEIRO, 2010, p. 25, grifo do autor).

Neste sentido, destaca-se que a pesquisa, o ensino e a prática têm interação dinâmica, ou seja, "é necessário pesquisa para elaborar respostas teóricas, e relacioná-las com o ato de ensinar, para [...] encontrar soluções práticas ao aplicar novos conhecimentos e habilidade para abordar novos problemas - que ainda venham a surgir" (ARAÚJO; SASTRE, 2016, p. 21). Ademais, o processo da ABP propõe desenvolver a autonomia do discente, além da competência individual sobre o ato de aprender e sobre o controle exercido aos procedimentos, aos conceitos, ao progresso do conhecimento e dos resultados, ou seja, "o desenvolvimento da autonomia na aprendizagem se baseia em outras habilidades ou capacidades que os alunos já têm" (ARAÚJO; SASTRE, 2016, p. 165).

Ribeiro (2010) enfatiza que a ABP é centrada no estudante e, por isso, as oportunidades de aprendizagem devem ser condescendentes para os discentes e para os objetivos da aprendizagem, sendo determinadas pelos que aprendem. Isso posto, delega-se ao estudante a responsabilidade da própria aprendizagem, criando um praticante para toda a vida. Contudo, "é necessário reafirmar que os alunos são, em última análise, sempre responsáveis pela aprendizagem, independentemente da metodologia de ensino adotada. Nada, nem ninguém, 
pode forçá-los a aprender se eles mesmos não se empenharem" (RIBEIRO, 2010, p. 35).

No que tange ao docente, Sastre e Araújo (2016, p. 34, grifo dos autores) destacam a mudança do papel do educador na ABP:

Tirar o foco do ensino e colocá-lo na aprendizagem modifica o papel do docente, que é de transmissor do conhecimento e facilitador do processo de aprendizagem. [...] Todos os alunos têm de saber explicar os resultados de seus estudos e pesquisas aos colegas do grupo. Essa exigência talvez indique aquisição dos conhecimentos profissionais e teóricos, o que só acontece quando o aluno é capaz de explicá-los aos demais.

Além disso, Ribeiro (2010, p. 36) enfatiza que a ABP:

[...] demanda do docente um papel diverso daquele geralmente encontrado [nas instituições], isto é, o professor palestrante, legitimador e transmissor de conhecimentos, trabalhando isoladamente, frequentemente mais interessado em suas pesquisas queem sua prática educacional. Em vez de transmitir o conhecimento, o docente deve, idealmente, interagir com os alunos no nível metacognitivo, ou seja, fazendo-lhes perguntas [...] e questionando seu raciocínio superficial e suas noções vagas e equivocadas. Esse novo papel de orientador, co-aprendiz, facilitador na construção do conhecimento [...], é um dos grandes desafios que o PBL coloca aos docentes e às instituições. Saber trabalhar com grupos de alunos e saber ensinar os alunos a trabalharem conjuntamente não é algo em que a maioria dos docentes tem experiência.

Para o desenvolvimento de processos de ABP, podem ser utilizadas metodologias ativas, em que o discente constrói aulas muito mais vivas e interessantes, tornando a relação entre todos os atores de uma sala de aula corresponsáveis pelo conhecimento, capazes de um planejamento conjunto e participativo. As metodologias ativas propiciam maior interação em sala e exige comprometimento de todos para se desenvolverem, resultando em estudantes motivados a frequentar as aulas e interessados em construir o saber. As metodologias ativas buscam desenvolver o processo de aprendizagem que os docentes utilizam na condução da formação crítica de profissionais nas mais diferentes áreas, assim sendo, favorecem a autonomia do discente, desperta a curiosidade, estimula a tomada de decisões, inclui o estudante nas atividades sociais (BORGES; ALENCAR, 2014).

Nas metodologias ativas o discente mergulha na própria aprendizagem, já que suas habilidades são incitadas, ele busca informação, adquire conhecimento, conecta conteúdos, compara teoria e prática (RIBEIRO, 2010). Da mesma forma, o discente assimila situações, compara-as e organiza uma 
análise crítica sobre a realidade, assim, torna-se um profissional preparado para os desafios futuros, observando que o mercado busca profissionais preparados para resolver problemas cada vez mais complexos e pluridisciplinares (BORDENAVE; PEREIRA, 2004).

Por isso, o docente deixa de ser o ator principal em aula e se torna um mediador do conhecimento, atuando conjuntamente com a turma, compartilhando conhecimento e motivando a crítica (BORDENAVE; PEREIRA, 2004). Ao contrário de aulas estritamente expositivas, ocorre a participação do estudante nas atividades, tarefas e trabalhos, buscando contextualizar situações e criando debates, além de desenvolver a aplicação prática dos conteúdos em estudo, ou seja, as metodologias ativas beneficiam o processo de aprendizagem. Por meio dela, adequa-se a realidade do estudante às circunstâncias em sala de aula, ao invés do discente receber conteúdos e exercícios prontos, ele realiza pesquisas e discussões. Berbel (2011, p. 27), ao defender a necessidade de uma maior autonomia do estudante em sua aprendizagem, afirma que:

[...] concorrem para a promoção da autonomia as atividades de aprendizagem que possibilitam, por exemplo [...], que, em relação a um dado comportamento, haja envolvimento pessoal, baixa pressão e alta flexibilidade em sua execução, e percepção de liberdade psicológica e de escolha.

De acordo com Ribeiro (2010, p. 32, grifo do autor), nas metodologias de aprendizagem ativas, que estão centradas no estudante, existem três categorias:

- Desafios acadêmicos: problemas de advêm da estruturação de conteúdos de uma área de estudo e, ainda que sejam utilizados principalmente para favorecer o entendimento de um assunto selecionado, servem também para desenvolver a capacidade de construir conhecimento e trabalhar colaborativamente.

- Cenários: problemas em que os alunos assumem papéis condicionantes com suas futuras atuações profissionais em contextos da vida real ou em cenários fictícios (simulações), nos quais começam a se ver em papéis reais na medida em que desenvolvem os conhecimentos e habilidades necessários para serem bem-sucedidos na escola e além desta.

- Problemas da vida real: problemas que pedem soluções reais por pessoas ou organizações reais e envolvem diretamente os alunos na explicação de uma área de estudo, cujas soluções são potencialmente aplicáveis em seus contextos de origem.

O uso de metodologias ativas podem ser aplicado em games, análises de casos, atividades práticas, atividades de campo, entre outros métodos (DONATO; GHILARDI, 2018). Bastos (2010, p. 10) conceitua metodologias ativas como o "processo interativo de conhecimento, análise, estudos, pesquisas 
e decisões individuais ou coletivas, com a finalidade de encontrar soluções para um problema". Por isso, aprender por intermédio de resolução de problemas e meios ativos no processo de formação exige estratégias e técnicas que possibilitem a construção dos resultados esperados.

\section{METODOLOGIA}

Este estudo é uma pesquisa aplicada que "objetiva gerar conhecimentos para aplicação prática dirigidos à solução de problemas específicos. Envolve verdades e interesses locais" (PRODANOV; FREITAS, 2013, p. 51). Também é um estudo de caso, "no qual se busca a aplicação prática de conhecimentos para a solução de problemas sociais [...], estão voltados mais para a aplicação imediata de conhecimentos em uma realidade circunstancial, relevando o desenvolvimento de teorias" (PRODANOV; FREITAS, 2013, p. 60).

Do mesmo modo, é uma pesquisa-ação, pois, foi "concebida e realizada em estreita associação com uma ação ou com a resolução de um problema coletivo. Os pesquisadores e participantes representativos da situação ou do problema estão envolvidos de modo cooperativo ou participativo" (KAUARK; MANHÃES; MEDEIROS, 2010, p. 29). Além disso, é uma pesquisa qualitativa que:

[...] considera que há uma relação dinâmica entre o mundo real e o sujeito, isto é, um vínculo indissociável entre o mundo objetivo e a subjetividade do sujeito que não pode ser traduzido em números. A interpretação dos fenômenos e a atribuição de significados são básicas no processo de pesquisa qualitativa. Não requer o uso de métodos e técnicas estatísticas. (KAUARK; MANHÃES; MEDEIROS, 2010, p. 26).

O estudo foi realizado durante a disciplina de Saúde do Idoso, ministrada aos estudantes do curso Técnico de Enfermagem, de uma Instituição de Ensino Superior localizada no Vale do Taquari-RS. A disciplina ocorreu entre os meses de agosto de outubro de 2019. Os resultados foram obtidos por meio das soluções apresentadas pelos discentes, expostos em sala de aula de forma expositiva e explicativa.

\section{ANÁLISE DOS RESULTADOS}

Os estudantes foram instruídos a buscar um problema relacionado à qualidade de vida do idoso, devendo apresentar uma solução para a problemática que visasse à melhoria da qualidade de vida desta população. No que tange a conceituação de qualidade de vida, Lima et al. (2018, p. 181) conceituam como a "percepção o indivíduo de sua posição na vida, no contexto da cultura e sistemas de valores nos quais vive em relação aos seus objetivos, expectativas, padrões e preocupações". 
Ainda, segundo a Organização das Nações Unidas (ONU), o período de 1975 a 2025 é considerado a "Era do Envelhecimento", destacando-se que, nos países em desenvolvimento, o envelhecimento populacional está sendo significativo e acelerado; analisando-se os anos de 1970 a 2000, observa-se um crescimento de $123 \%$ nesta população nestes países e, nas nações desenvolvidas o crescimento foi de $54 \%$ neste mesmo período (ANDRADE; MARTINS, 2011).

Dada a relevância dos fatos expostos e em detrimento da disciplina Saúde do Idoso, os discentes buscaram, no convívio familiar, contextos que fomentassem sua problemática, trazendo informações. Discutiu-se sobre as problemáticas, planejou-se possibilidades de soluções e, na prática, foram apresentadas soluções às necessidades dos idosos. Para esta prerrogativa utilizou-se, de forma a incorporar os preceitos de Ribeiro (2010), em que as metodologias ativas centram-se no estudante, que é desafiado a estudar problemáticas que visem compreensão do assunto, ao mesmo tempo em que se apresentam cenários condizentes com a sua atuação profissional por meio de simulações embasadas na realidade, finalizando-se por soluções a problemas reais que envolvam diretamente o estudante a explicar e aplicar seus conhecimentos.

Das propostas da aprendizagem baseada em problemas, ou seja, da necessidade de melhoria da qualidade de vida do idoso, surgiram duas soluções:

- Andador que vira assento, com o intuito do idoso debilitado ou usuário fazer caminhadas leves sem precisar de auxílio e poder sentar-se para um descanso.

- Bengala com suporte interno para medicamentos, facilitando o transporte de medicamentos em pequenos compartimentos da bengala, evitando a fadiga de carregar sacola ou outros suportes maiores quando em locomoção externa à residência.

\subsection{Andador que vira assento}

O problema surgiu da percepção de um estudante dentro do seio familiar, a qual relata: "Aos 63 anos minha vó teve um AVC leve, caiu e fraturou um osso da bacia. Durante a recuperação ela usava um andador. Meu vô sempre a seguia com uma cadeira, pois cansava muito rápido" (Discente A).

Diante da problemática trazida pela discente o grupo de estudantes discutiu possibilidades de melhorar a vida e as necessidades de pessoas que estão em situações parecidas. Foram realizadas pesquisas sobre materiais e métodos que pudessem auxiliar na construção prática dessa solução. O grupo em discussão concluiu que poderiam criar um andador que vira assento, tendo como objetivo e finalidade usar também na hora do banho e como cadeira. 
Os materiais utilizados para a solução desta problemática foram: Cano de PVC, emendas de PVC, tampa de PVC, curvas (joelho) de PVC, arame de alumínio, tábua de madeira, tinta spray preta e cinta plástica.

Para a confecção do andador, os estudantes realizaram a medição dos canos de PVC, por conseguinte, realizaram os encaixes dos canos, emendas e curvas. Para a estrutura dos pés utilizaram as tampas de PVC. Na sequência, cortaram a tábua no tamanho ideal para o encaixe no andador. $\mathrm{O}$ assento foi fixado com o auxílio do arame e das cintas de plástico. Por fim, fez-se o acabamento com tinta spray na cor preta.

Ao encontrarem o resultado a discente A, que trouxe a problemática, relatou que "Ao usar o andador quando se cansar seria uma maneira mais ágil e prática, pois só precisaria puxar e sentar sem precisar do auxílio de outra pessoa".

O resultado deste andador é exposto na Figura 1:

Figura 1 - Andador que vira assento

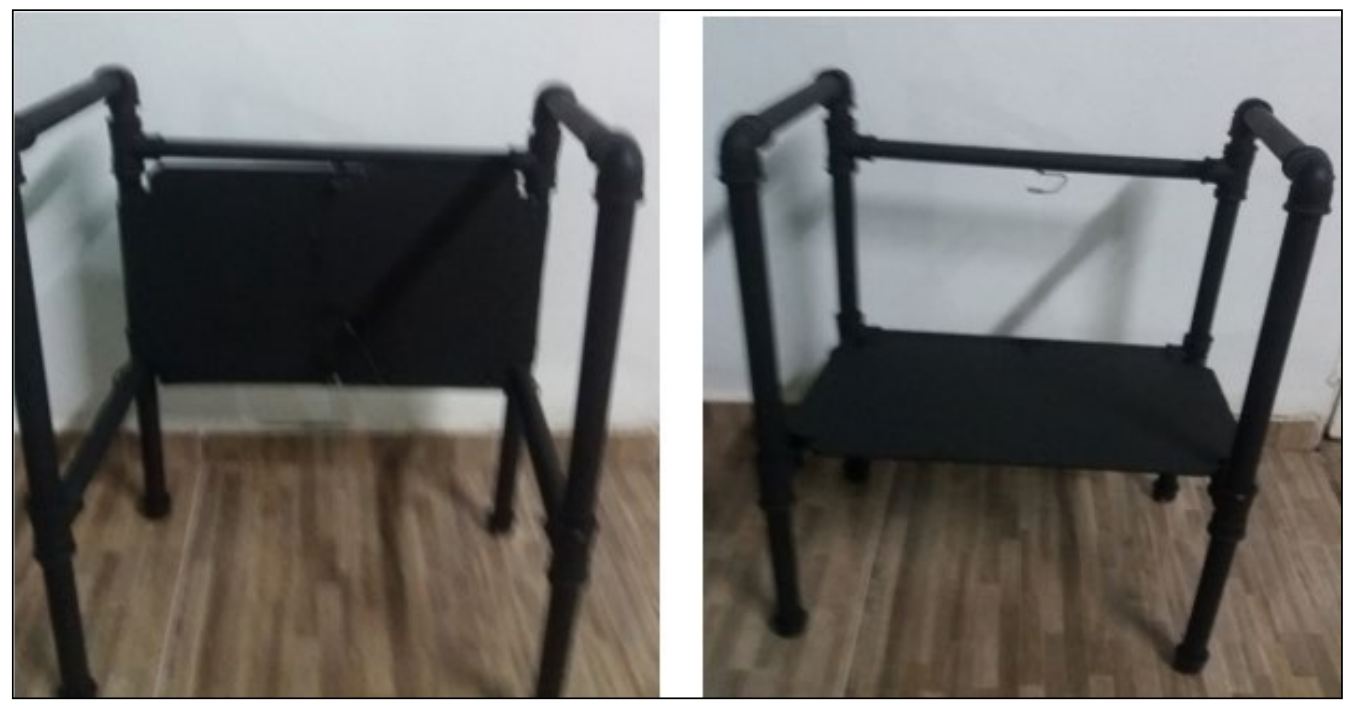

Fonte: Dos autores (2019).

O grupo de estudo revelou que o andador foi pensado para garantir o máximo de praticidade ao dia a dia de pessoas que possuem restrições de mobilidade, além disso, para indivíduos em que essa necessidade é por um curto período de tempo, as funcionalidades podem ajudar em uma recuperação mais rápida e independência. Em contraponto, para os indivíduos que possuem problemas permanentes ou que a recuperação é longa, o principal benefício está em obter mais conforto durante o período de uso. Além disso, o andador com assento é excelente para quem irá se locomover por espaços externos, pois se a caminhada ficar cansativa, o paciente tem a chance de parar por alguns minutos e descansar com o auxílio do próprio andador. 
A utilização de materiais de baixo custo e de fácil montagem facilita o acesso às pessoas carentes, que muitas vezes, não tem acesso aos diversos equipamentos disponíveis no mercado para este fim, como cadeira de rodas, cadeira para tomar banho, cadeira para sanitário, andadores e etc. que, muitas vezes, têm custos elevados.

\subsection{Bengala sustentável com compartimento interno para medicamentos}

A partir do princípio de outras bengalas criadas no século XIX, detentoras de segredos inusitados, surgiu a ideia de uma bengala sustentável com compartimento interno para guardar medicação; a ideia surgiu depois de brincadeiras do grupo, envolvendo a utilidade de uma bengala, como "esconder azulzinhos", objetivando facilitar o transporte de medicamentos disponíveis em pequenos compartimentos na bengala, evitando o desconforto de carregar sacolas ou outros suportes maiores na locomoção do indivíduo. Além disso, com pensamento sustentável, optou-se por utilizar bambu no processo de fabricação, pois é um material resistente e durável, bem como, dá um toque rústico e charmoso ao protótipo.

A bengala foi produzida com bambu, utilizando-se cola quente para acoplar as divisórias, encaixes e pé de apoio, afinal é um produto fácil de moldar, que dá firmeza e apoio antiderrapante. Para o suporte de medicamentos foram utilizadas dobradiças de metal e um pequeno recipiente plástico para transporte de líquidos (água para tomar os medicamentos).

Figura 2 - Bengala sustentável com compartimento interno para medicação

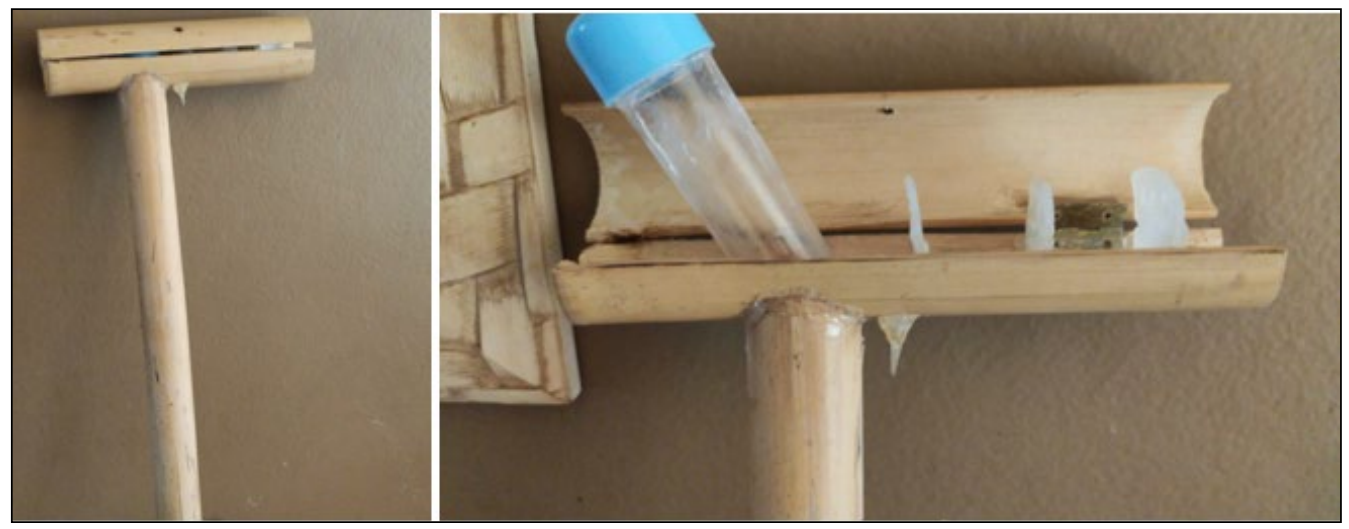

Fonte: Dos autores (2019).

Os integrantes relataram que foi um projeto simples e que pode ser usado pelos idosos como um instrumento de auxílio e praticidade para o dia a dia, sendo facilmente adaptado à sua altura, e personalizado em seu suporte conforme suas reais necessidades. Não se encontra nada parecido em outros 
estudos ou meio eletrônico variado, evidenciando-se a inovação e rusticidade do protótipo, que, ao mesmo tempo, tem baixo custo e materiais de fácil acesso.

\section{CONSIDERAÇÕES FINAIS}

$\mathrm{O}$ atendimento dos profissionais de enfermagem busca o cuidado e bem estar de pacientes. A partir desta ótica, pensar a construção do conhecimento discente como uma perspectiva às necessidades profissional-paciente favorece o desenvolvimento de ações, atitudes e soluções inesperadas e fáceis. Utilizar metodologias ativas e a aprendizagem baseada em problemas contribui para provocar a dinâmica profissional necessária ao futuro profissional técnico de enfermagem.

Por meio de "provocações" e estímulos aos discentes para que desenvolvessem um projeto inovador visando qualidade de vida ao idoso, surgiram dois projetos: 1) andador que vira assento e 2) bengala sustentável com compartimento para medicamentos. Os dois projetos evidenciam mobilidade de pessoas com dificuldade de locomoção; o andador contribui para que as caminhadas sejam realizadas com paradas para descanso; já a bengala auxilia para que o indivíduo não necessite carregar bolsas ou sacolas com medicamentos e líquidos.

É perceptível que a construção da aprendizagem realizada com o protagonismo discente contribui para a compreensão profissional, além de trazer resultados dinâmicos e simples sobre fatos e atos da realidade dos envolvidos: idoso e estudante. Por fim, salienta-se que novos estudos e estímulos devem ser realizados em outras turmas, buscando melhorias contínuas tanto na aprendizagem como na melhoria da vida das pessoas.

\section{REFERÊNCIAS}

ARAÚJO, Ulisses F.; SASTRE, Genoveva (Orgs.). Aprendizagem baseada em problemas no ensino superior. 3. ed. São Paulo: Summus, 2016.

ANDRADE, Ana Isabel N. P.; MARTINS, Rosa Maria L. Funcionalidade Familiar e Qualidade de Vida dos Idosos. Millenium, v. 40, p. 185-199, 2011.

LIMA, Luciano Ramos et al. Qualidade de vida e o tempo do diagnóstico do diabetes mellitus em idosos. Rev. Bras. Geriatr. Gerontol., v. 21, n. 2, p. 180-190, 2018.

BASTOS, C. C. Metodologias Ativas. 2006. Disponível em: <http:/ / educacaoemedicina.blogspot.com.br/2006/02/metodologias-ativas.html>. Acesso em: 20 fev. 2020.

BERBEL, Neusi A.N. As metodologias ativas e a promoção da autonomia de estudantes. Semina: Ciências Sociais e Humanas, v. 32, n. 1, p. 25-40, 2011. 
BORDENAVE, Juan D.; PEREIRA, Adair M. Estratégias de ensino-aprendizagem. 25. ed. Petrópolis: Vozes, 2004.

BORGES, Tiago Silva; ALENCAR, Gidélia. Metodologias ativas na promoção da formação crítica do estudante: o uso das metodologias ativas como recurso didático na formação crítica do estudante do ensino superior. Cairu em Revista, ano 03, n. 04, p. 119-143, jul./ago. 2014.

DONATO, Sueli Pereira; GHILARDI, Rossana. Aprendizagem na modalidade semipresencial: representações sociais de estudantes de licenciaturas. In:

CONGRESSO INTERNACIONAL DE EDUCAÇÃO E TECNOLOGIAS, 26 jun. a 13 jul. 2018. Anais... [S.1.]: Uninter, 2018. 13p.

FERREIRA, Sandra Lúcia; CONDORI, Raul Claudio Choquehuanca; SOUZA, Fernanda Evelin Camarço. Políticas públicas para saúde e educação: conceito de humanização na formação de enfermeiros. Revista ambiente educação, v. 12, n. 3, p. 154-169, 2019.

KAUARK, Fabiana; MANHÃES, Fernanda Castro; MEDEIROS, Carlos Henrique. Metodologia da pesquisa: guia prático. Itabuna: Via Litterarum, 2010.

OLIVEIRA, Marlene Gonçalves; PONTES, Letícia. Metodologia ativa no processo de aprendizado do conceito de cuidar: um relato de experiência. In: CONGRESSO NACIONAL DE EDUCAÇÃO, 10., 07 a 10 nov. 2011. Anais... Curitiba: PUC-PR, 2011. p. 8167-8177.

PRODANOV, Cleber Cristiano; FREITAS, Ernani Cesar. Metodologia do trabalho científico [recurso eletrônico]: métodos e técnicas da pesquisa e do trabalho acadêmico. 2. ed. Novo Hamburgo: Feevale, 2013.

RIBEIRO, Luis R. C. Aprendizagem baseada em problemas (PBL): um experiência no ensino superior. São Carlos: EdUFSCar, 2010. 